\title{
INFORME \\ Que se presenta al Colegio Electoral de la H. Cámara de Diputados del Congreso de la Unión
}

\section{Jorge Carpizo}

26 de octubre de 1994 


\section{Antecedentes}

El presente Informe constituye un anexo al aprobado por el Consejo General del Instituto Federal Electoral y, de acuerdo a lo dispuesto por el inciso t del párrafo 1 del Artículo 82 del Código Federal de Instituciones y Procedimientos Electorales es remitido a los CC. Secretarios de la LVI Legislatura de la Cámara de Diputados del H. Congreso de la Unión.

Desde luego el único responsable de este informe soy yo, en mi carácter de Presidente del Consejo General del Instituto Federal Electoral, aunque agradezco el invaluable apoyo que me han presentado en su redacción los Licenciados Jorge Alcocer y Manuel Barquín.

El proceso electoral federal de 1994 se desarrolló en circunstancias particulares, producto de acontecimientos que obligaron al Gobierno de la República a reforzar medidas destinadas a garantizar la seguridad de los ciudadanos y salvaguardar la paz social, así como a dar respuesta inmediata a exigencias planteadas por distintos grupos sociales y por los partidos políticos nacionales.

Los sucesos acaecidos en el estado de Chiapas a partir del 1 de enero de 1994 produjeron una serie de cambios en la política del Gobierno Federal. Por decisión del Titular del Ejecutivo de la Unión, el 10 de enero del año en curso, asumí la titularidad de la Secretaría de gobernación y en consecuencia, por mandato de Ley, la Presidencia del Consejo General del Instituto Federal Electoral. Por instrucciones del C. Presidente de la República, desde el primer día de mi ejercicio en el cargo busqué el contacto y el diálogo con todas las fuerzas políticas del país. El objetivo expreso era buscar acuerdos políticos que permitieran el desarrollo de las elecciones federales de agosto en tiempo y forma, y en condiciones que garantizaran la legalidad y limpieza de las mismas.

Para ese efecto dialogué con los dirigentes nacionales de todos los partidos políticos, así como con sus precandidatos a la Presidencia de la República. Entre otros aspectos, de esos diálogos bilaterales, en los que fui eficientemente apoyado, surgió la idea de un Acuerdo Nacional entre los partidos políticos que expresara el firme compromiso de todos con la legalidad y la civilidad como únicas vías para dirimir las diferencias políticas entre los mexicanos. Los acontecimientos de 
Chiapas exigían respuestas claras y rápidas con el fin de preservar la paz y extender la justicia y la democracia.

En todos los partidos y candidatos encontré firme compromiso con la República y sus Instituciones, con la preservación del Estado de Derecho, y una clara disposición de diálogo y la búsqueda de acuerdos para avanzar en la democratización del país. Como producto de esos encuentros, el 27 de enero de 1994, ocho de los nueve candidatos presidenciales suscribieron el Acuerdo Nacional por la Paz, la Justicia y la Democracia, documento en el cual quedaron establecidos los objetivos a los que partidos y Gobierno nos comprometimos para asegurar la celebración de las elecciones de agosto de 1994 en condiciones de legalidad y limpieza. Cabe anotar, que incluso el Partido Popular Socialista, que no aceptó suscribir el citado Acuerdo, mantuvo siempre un diálogo fructífero con el presidente del Consejo General del IFE, aportando ideas y propuestas al diálogo nacional.

En el Acuerdo del 27 de enero nos comprometimos a que fuese el diálogo la vía para llegar a los cambios, y que el consenso sería el método para la toma de decisiones, entendiendo éste no como la imposible unanimidad, sino como la construcción de soluciones compartidas que dieran satisfacción a los reclamos de cada partido. Consenso no es unanimidad, sino flexibilidad para acercar posiciones y llegar a soluciones que quizá no satisfagan a plenitud lo que cada uno quiere, pero que representan un avance para todos.

\section{Las conversaciones de Barcelona}

A principios de febrero de 1994 dieron inicio las conversaciones entre los partidos políticos y el Secretario de Gobernación y presidente del Consejo General del IFE. Por razones políticas y operativas las pláticas se desarrollaron en dos instancias paralelas. En una participaron los presidentes nacionales de los partidos Acción Nacional, Revolucionario Institucional y de la Revolución Democrática - partidos que en conjunto habían recibido más del $90 \%$ de la votación nacional en la última elección federal- y el Secretario de Gobernación. En la segunda instancia se creó una mesa para el diálogo y la recepción de propuestas surgidas de los partidos Popular Socialista, Auténtico de la Revolución Mexicana, Frente Cardenista de Reconstrucción Nacional, Demócra- 
ta Mexicano, del Trabajo y Verde Ecologista de México, con quienes también con frecuencia el Secretario de Gobernación se reunió.

Esa división del trabajo fue objeto de diversas críticas, pero estoy convencido de que tenía base en una política objetiva y sobre todo era necesaria puesto que el tiempo disponible para arribar a acuerdos era limitado, dada la cercanía de la fecha para la celebración de la jornada electoral. A ningún partido se negó la posibilidad de externar puntos de vista y realizar propuestas, todas ellas fueron consideradas y analizadas con seriedad y objetividad. El Secretario de Gobernación y presidente del Consejo General del IFE sostuvo múltiples reuniones bilaterales y multilaterales con los seis partidos que integraron la segunda mesa de negociaciones. Nunca antes un Secretario de Gobernación sostuvo un diálogo tan intenso con todos los partidos políticos como el desarrollado entre el 8 de enero a esta fecha.

Las conversaciones entre el Secretario de Gobernación y los representantes de los tres mayores partidos políticos de México tuvieron lugar de principios de febrero hasta el mes de julio del presente año. La sede de las conversaciones fue la casa marcada con el número 32 de la calle de Barcelona en la Ciudad de México. De ahí que la prensa nacional haya denominado a los acuerdos ahí alcanzados "Los Acuerdos de Barcelona". Sin embargo, cabe aclarar que las conversaciones tuvieron lugar tanto en el local antes citado como en las instalaciones del Instituto Federal Electoral.

Por la naturaleza y fines del diálogo no se levantó registro alguno del desarrollo de las conversaciones. Estas no fueron grabadas ni existieron actas de cada sesión. Cada uno de los participantes tomó nota del desarrollo de cada sesión, y los acuerdos, cuando a ellos se arribó, fueron plasmados en documentos de consenso que, por acuerdo de los partidos, no fueron del dominio público. Sin embargo, los acuerdos que merecieron el consenso constituyeron después la base para la presentación de proyectos de resolución ante el Consejo General del IFE, o bien Iniciativas de Reformas a la Constitución General de la República, al Código Federal de Instituciones y Procedimientos Electorales y al Código Penal.

En todo momento los participantes en las negociaciones fueron respetuosos de las competencias que la Constitución y las leyes confieren a los distintos órganos electorales, legislativos y gubernamentales. Sus acuerdos fueron remitidos como propuestas a cada órgano competente para su consideración y, en su caso, implantación. 
El diálogo de Barcelona tuvo, en lo que hace a sus participantes, dos etapas claramente definidas; el hecho que lo motivó fue la trágica muerte del candidato presidencial del Partido Revolucionario Institucional, Lic. Luis Donaldo Colosio Murrieta. La primera etapa de las conversaciones se desarrolló de febrero a marzo de 1994, mientras que la segunda etapa abarcó de abril a julio del mismo año.

Para claridad de los hechos, y conocimiento de los integrantes del Colegio Electoral, es pertinente informar de los participantes permanentes en el diálogo de Barcelona:

Por el Partido Acción Nacional: CC. Carlos Castillo Peraza, Felipe Calderón y Antonio Lozano Gracia.

Por el Partido Revolucionario Institucional: el CC. Fernando Ortiz Arana y Santiago Oñate Laborde; Ignacio Pichardo Pagaza, José Francisco Ruiz Massieu (qepd) y Humberto Lira Mora.

Por el Partido de la Revolución Democrática: CC. Porfirio Muñoz Ledo y Ricardo Valero.

Por la Secretaría de Gobernación: CC. Jorge Carpizo, Tristán Canales y Beatriz Paredes.

Por el Instituto Federal Electoral: CC. Jorge Carpizo y Arturo Núñez.

Como Consejero personal del presidente del Consejo General del IFE: C. Jorge Alcocer V.

En lo que hace a la segunda mesa de diálogo, los participantes en las reuniones bilaterales y multilaterales fueron los funcionarios de la Secretaría de Gobernación antes citados; el Presidente del Consejo General y el Director General del IFE, y los CC. Representantes de los Partidos Políticos ante el Consejo General del IFE, así como en múltiples ocasiones los dirigentes nacionales de los partidos políticos.

La base de las conversaciones fue el Acuerdo Nacional para la Paz, la Justicia y la Democracia, suscrito el 27 de enero de 1994 - del cual anexo copia-. La primera tarea a la que se avocaron los representantes partidistas fue definir la agenda para dar cumplimiento a los objetivos plasmados en dicho Acuerdo.

Después de intercambiar puntos de vista, y ante la propuesta del PRD en el sentido de que hubiese un acuerdo de que habría reformas constitucionales y legales, los partidos se comprometieron a que de llegarse a consensos que requiriesen cambios legales, la correspondiente propuesta sería sometida a la consideración del H. Congreso 
de la Unión. Pero que ese tema era un punto de llegada de las conversaciones, y no un presupuesto de las mismas.

Aceptando lo anterior, se convino en iniciar los intercambios de puntos de vista sobre los temas que enseguida enuncian:

1) Idoneidad de los Funcionarios del IFE a todos los niveles, conforme a los objetivos expresados en el Acuerdo del 27 de enero.

2) Padrón electoral y credenciales para votar con fotografía. Auditoría externa y otras formas de verificación.

3) Acceso de los partidos políticos a los medios de comunicación electrónicos - radio y televisión-.

4) Acciones del Gobierno Federal para garantizar mejores condiciones de equidad en la competencia electoral.

Esa fue la primera agenda convenida; después, en el curso mismo de las conversaciones en ambas mesas, surgieron nuevos temas, nuevas propuestas, que terminaron por convertirse en puntos esenciales de las reformas que propició el Acuerdo del 27 de enero.

Llevar al detalle este Informe desbordaría su sentido y las necesidades de la Cámara de Diputados del H. Congreso de la Unión. Mi objetivo es dar cuenta de los aspectos fundamentales de las conversaciones interpartidistas y de los partidos con el representante del Gobierno Federal. Del esfuerzo de todos los partidos surgieron las reformas legales y procedimentales que permitieron la realización de las elecciones federales del 21 de agosto de 1994 en un marco de legalidad, civilidad y concordia.

El juicio sobre este momento de nuestra historia corresponde a los especialistas de esa disciplina de las Ciencias Sociales, y sobre todo al pueblo de México.

Doy testimonio de mi verdad, la sustento en hechos y apreciaciones; los primeros son objetivos, las segundas son mi particular valoración de un periodo particularmente complejo de la vida nacional. He tratado de ser imparcial. Otros testimonios completarán la visión y enriquecerán el juicio de los CC. Diputados miembros del Colegio Electoral.

Para enriquecer su visión y su criterio, remito, con el presente documento, copia de tres documentos que completan el presente Informe: 
- El texto del discurso que pronuncié el 21 de marzo de 1994 en Querétaro, Qro.

- El texto de mi intervención ante el Consejo General del Instituto Federal Electoral el 3 de junio de 1994.

- El texto del discurso que pronuncié en la ceremonia de entrega de reconocimientos a los Ciudadanos, Funcionarios de Mesas de Casilla e integrantes del Consejo Técnico del Padrón Federal Electoral el 12 de septiembre de 1994.

Al igual que en este Informe, en esos textos expresé $m i$ verdad. No pretendo que sea la verdad. Esa corresponde al pueblo, y escribirla toca, como dije antes, a los historiadores, aunque en lo personal me propongo profundizar en esa historia para dársela a conocer a la sociedad.

\section{Revocación de funcionarios del IFE}

Por acuerdo de los partidos, y por haber sido un compromiso adoptado el 27 de enero, el primer punto de la agenda de la negociación se refirió a este aspecto. Cabe recordar el texto relativo tal y como quedó plasmado en el Acuerdo por la Paz, la Justicia y la Democracia:

Para una elección imparcial:

1. Imparcialidad de las autoridades electorales, eligiendo o ratificando para cada uno de los niveles a ciudadanos aptos y honestos.

El criterio que guiará el nombramiento o ratificación citadas será el de la consulta y el consenso entre las fuerzas políticas.

Conforme a ese criterio, los partidos políticos definieron el 9 de febrero de 1994 una metodología y unos plazos para llevar a cabo la revisión de los funcionarios electorales a todos los niveles, así como para realizar la revisión de los consejeros magistrados y consejeros ciudadanos de los órganos de dirección del IFE. El plazo originalmente convenido para concluir estos trabajos fue el 5 de marzo; sin embargo, a solicitud de los propios partidos, la fecha límite fue prorrogada en varias oportunidades, hasta llegar al 27 de mayo, día en el que el proceso de revisión quedó prácticamente concluido, quedando pen- 
dientes un pequeño número de casos, que fueron desahogados en el curso del mes siguiente.

Como resultado del análisis realizado por una subcomisión especial, integrada por representantes de los partidos y los funcionarios del IFE responsables del área del Servicio Profesional Electoral, fueron substituidos 34 vocales locales, 212 vocales distritales y 122 consejeros ciudadanos. Si no hubo un mayor número de cambios fue o porque los partidos no presentaron impugnación alguna, o porque no se consideró, por alguno de ellos, procedente la impugnación.

Reitero que en todos los casos de sustitución los criterios para aprobar el cambio estuvieron vinculados a la idoneidad política del funcionario sustituto, sin que en ningún caso haya sido puesta en duda o cuestionada la honorabilidad personal de los funcionarios impugnados.

Como era natural, el proceso de sustituciones introdujo en toda la estructura del IFE un clima de inestabilidad que pudo ser superado gracias a la voluntad de cooperación de todos los funcionarios y al espíritu de responsabilidad que mostraron los partidos políticos en esta delicada tarea.

Los partidos políticos plantearon la pertinencia del cambio de Director General del IFE. Pese a que el Director había sido nombrado por 8 años, con el voto favorable de todos los integrantes del Consejo General y sólo la abstención de un partido y del Consejero de la primera minoría de la Cámara de Senadores, y pese a que todos los partidos reconocieron su aptitud y profesionalismo; en mi carácter de presidente del Consejo General del IFE, y previo acuerdo del Director General, acepté que el tema fuese discutido y analizado en la mesa de Barcelona.

Los tres mayores partidos llegaron al consenso sobre la pertinencia de nombrar un nuevo Director General del IFE y confirieron al presidente del Consejo la tarea de proponer candidatos a dicho puesto. Ninguna de las propuestas presentadas alcanzó el consenso.

De igual forma, habiéndose solicitado el cambio en varias de las Direcciones Ejecutivas, no se llegó al consenso entre los partidos.

Ante la renuncia del Director Ejecutivo de Prerrogativas y Partidos Políticos, hecho ocurrido en el curso de las conversaciones de la mesa de Barcelona, los partidos convinieron en admitir que uno de ellos hiciera la presentación de la propuesta de candidatos a ocupar ese cargo. La propuesta fue aprobada el 3 de junio de 1994 por el nuevo Consejo General del IFE. 


\section{Nueva integración del Consejo General}

Pese a que no formaba parte de los compromisos del 27 de enero, los partidos y la autoridad electoral convinieron la pertinencia de analizar y en su caso modificar la integración de funciones de los Órganos de Dirección del Instituto Federal Electoral. Ello se hizo necesario ante la insistencia de los representantes del PRD en el sentido de dar cabal cumplimiento a compromisos adaptados en anteriores procesos de reforma, en particular al principio general conforme al cual en el órgano superior de dirección electoral debía garantizarse una integración que impidiera que cualquier partido, o alianza formal o informal de partidos, o de uno o varios de ellos con los representantes de los Poderes Públicos, pudiese tener una mayoría predeterminada.

Además, los partidos convinieron en someter a discusión la figura de los llamados "Consejeros Magistrados" Miembros del Consejo General de IFE, en particular la disposición contenida en el artículo 41 constitucional de que los ciudadanos designados para ese cargo cumplieran el requisito de ser abogados. La supresión de ese requisito fue consensada por los partidos, lo que llevó al siguiente acuerdo que consistió en cambiar su denominación por la de "Consejeros Ciudadanos" y a la modificación de la forma para su nombramiento.

Como se recordará, producto de la Reforma Constitucional de 1990 y del Código Federal de Instituciones y Procedimientos Electorales, aprobado y promulgado en ese mismo año, correspondía al Presidente de la República el derecho de enviar a la Cámara de Diputados la lista de propuestas para Consejeros Magistrados, cuyo nombramiento debía ser aprobado por dos terceras partes de los diputados. Los partidos convinieron en proponer al H. Congreso de la Unión la modificación del procedimiento para la designación, de forma tal que la propuesta correspondiera a los propios partidos, a través de sus Grupos Parlamentarios en la Cámara de Diputados, conservándose el requisito de la aprobación por mayoría calificada de dos tercios.

De esa forma, se abrió paso a la discusión sobre la conveniencia de proceder, para la elección de 1994, al nombramiento de los "Consejeros Ciudadanos", como uno de los pasos fundamentales en lo que desde entonces empezó a denominarse "proceso de ciudadanización de la autoridad electoral" 
A lo largo de cuatro meses los partidos analizaron propuestas presentadas por ellos mismos. Más de 50 candidaturas fueron comentadas, y después de algunas peripecias, se llegó a una lista de seis candidatos que merecieron el consenso de los tres mayores partidos.

La ciudadanización de los órganos de dirección electoral llevó de manera directa a la discusión sobre el papel y atribuciones de los partidos en dichos órganos. Al respecto se analizaron varias propuestas, en un primer momento, la que mereció consenso establecía que los partidos políticos con registro definitivo se harían representar en los órganos de dirección del IFE en forma paritaria y que cada uno tendría un representante con voz y voto. Los partidos que habían obtenido su registro en el periodo entre elecciones tendrían un representante con voz, pero sin voto.

Sin embargo, el PAN no pudo mantener su aceptación a dicha fórmula por razones internas, lo que motivó un nuevo intercambio de puntos de vista, del cual surgió la fórmula que finalmente mereció consenso y fue llevada como propuesta de reforma legal al $\mathrm{H}$. Congreso de la Unión: los partidos políticos nacionales tendrían igual representación en los órganos de dirección del IFE a todos los niveles, con un representante por partido con voz y sin voto.

$\mathrm{Al}$ analizar la presencia de los representantes de los Poderes Públicos en el Consejo General del IFE, los partidos convinieron en que el Secretario de Gobernación siguiese siendo, por mandato de ley, el representante del Poder Ejecutivo y presidente del Consejo General, y a propuesta de éste convinieron en recomendar la supresión del voto de calidad en caso de empate a dicho funcionario. La representación de las dos Cámaras del H. Congreso de la Unión se consideró satisfactoria en los términos vigentes por lo que no se propuso cambio en esa materia, mientras exista la representación del Poder Ejecutivo.

Tratándose de los órganos de dirección desconcentrados a nivel local y distrital, se convino en proponer la supresión del artículo décimo octavo transitorio del Decreto publicado el 24 de septiembre de 1993 por el cual se reforman, adicionan y derogan diversos artículos del COFiPE, y reformar el párrafo 1 de los artículos 102 y 103 del mismo ordenamiento, de forma tal que el número de consejeros ciudadano de esos órganos fuese similar al adoptado para el Consejo General del IFE - seis consejeros ciudadanos-; se convino además que el Vocal Secretario de la Junta Ejecutiva correspondiente perdiera el derecho 
de voto, y que los partidos políticos se representaran de la misma forma y con los mismos derecho que en el órgano superior de dirección. A mediados de marzo se llegó a la solución por consenso que dio lugar a la iniciativa de reformas constitucionales y reglamentarias que a través de sus Grupos Parlamentarios, tres partidos políticos, y posteriormente otro, sometieron a consideración del Constituyente Permanente y del $\mathrm{H}$. Congreso de la Unión.

La reforma constitucional publicada el 19 de abril de 1994 modificó el texto del artículo 41 de nuestra Carta Magna, cambiando la denominación de "Consejero Magistrado", por la de "Consejero Ciudadano", se suprimió la homologación de requisitos para ocupar ese cargo a los exigidos para ser Ministro de la Suprema Corte de Justicia, y se introdujo entre los principios rectores de la autoridad electoral el de "independencia". De igual forma, se modificó el procedimiento para la presentación de propuestas de consejeros ciudadanos a la Cámara de Diputados. El texto del artículo 41 en su conjunto fue reordenado para fines de mejor técnica jurídica y fácil comprensión.

De conformidad a la reforma del Código Federal de Instituciones y Procedimientos Electorales, publicada el 18 de mayo de 1994, los órganos de dirección del Instituto Federal Electoral quedaron integrados de la siguiente forma:

- Consejo General.

- Consejeros con voz y voto:

- Un Consejero representante del Poder Ejecutivo, que por ley es el Secretario de Gobernación, quien, también por mandato de ley, es presidente del Consejo.

- Dos consejeros por cada una de la Cámaras del H. Congreso de la Unión, uno propuesto por la mayoría y otro por la primera minoría en cada una de la Cámaras.

- Seis consejeros ciudadanos, electos por la Cámara de Diputados con mayoría calificada de dos tercios, de entre las propuestas presentadas por los Grupos Parlamentarios en la propia Cámara.

- Representantes de partido, con voz y sin voto:

- Un representante nombrado libremente por cada partido.

- Funcionarios superiores del IFE, con voz y sin voto:

- Director General del IFE.

- Secretario General del Consejo.

- Consejos Locales y Distritales: 
- Vocal Ejecutivo con voz y voto, preside el Consejo.

- Seis consejeros ciudadanos, con voz y voto.

- Un representante de cada partido político nacional, con voz y sin voto.

- Vocal Secretario, con voz y sin voto.

Adicionalmente, los partidos convinieron en proponer cambios en las facultades de los Consejos Locales y Distritales, de forma que las atribuciones sustantivas referidas al proceso electoral que tenían conferidas las Juntas Ejecutivas, pasaron a ser facultades de los respectivos Consejos.

Con la reforma aprobada por el H. Congreso de la Unión se produjo el cambio más significativo que México haya conocido desde la década de los cuarenta, cuando fue creada la primera Comisión Electoral de ámbito federal como órgano autónomo de los Poderes Públicos. La reforma abrió paso a la ciudadanización de nuestros organismos electorales.

Por vez primera en nuestra historia electoral contemporánea los partidos políticos carecen de voto. Los representantes de los Poderes Públicos no tienen mayoría de voto. Esa mayoría está conferida a los ciudadanos, son ellos quienes tienen la capacidad de decisión en todos y cada uno de los órganos de dirección del Instituto Federal Electoral. La reforma fue aún más profunda en los órganos de dirección desconcentrados - Consejos locales y distritales- pues en ellos, de siete votos posibles, seis corresponden a los consejeros ciudadanos. En el Consejo General del IFE, de 11 votos, seis corresponden a los consejeros ciudadanos.

El 3 de junio de 1994 quedó formalmente instalado el Consejo General del IFE acorde a las nuevas disposiciones constitucionales y legales.

\section{Padrón electoral}

El Acuerdo del 27 de enero de 1994 estableció referido a este tema, lo siguiente:

"2. Plena confiabilidad del padrón electoral, de las credenciales y las listas nominales, dado las garantías que han sido demandadas por 
los partidos y la opinión pública, entre ellas el acceso permanente a las bases de datos e imágenes del Registro Nacional de Electores y la auditoría externa del padrón respectivo".

Al considerar que a solicitud de varios partidos políticos el Consejo General del IFE había venido analizando desde el mes de agosto de 1993 la propuesta para la realización de una auditoría externa al padrón electoral y a la entrega de credenciales para votar con fotografía, se convino en pedir a los Consejeros Magistrados del Consejo General, quienes habían sido comisionados para elaborar la correspondiente propuesta, el avance de su trabajo.

Analizados los avances registrados por la Comisión, se convino en realizar un intercambio de opiniones entre los técnicos de los partidos políticos y los asesores de los Consejeros Magistrados, en presencia de los asistentes a las conversaciones de Barcelona.

Los representantes del PRD propusieron la realización de la técnica censal total como método de verificación de la confiabilidad del padrón. Pese a que el partido proponente nunca detalló su propuesta en términos de recursos, plazos y mecanismos de supervisión, la propuesta fue discutida en términos generales y con la información suministrada en forma verbal por su asesor técnico. Con la oposición del PRD, los demás partidos y asesores técnicos consultados llegaron a la conclusión de que la propuesta de dicho partido resultaba inviable en razón de los plazos disponibles, las normas legales aplicables y la seguridad del propio proceso electoral.

En consecuencia, se procedió a solicitar, de un grupo de expertos, la formulación de unos Términos de Referencia para la licitación pública de los trabajos de auditoría externa al Padrón Federal Electoral. El anteproyecto fue sometido de nueva cuenta a la revisión de los partidos políticos, los cuales hicieron sugerencias de agregados que pretendían hacer más rigurosos y complejos los trabajos de auditoría.

La mayor parte de esas propuestas fueron hechas por el PRD y fueron aceptadas, aprobándose finalmente el proyecto de Términos de Referencia. Sin embargo, al iniciar las consultas con las empresas que por su capacidad y seriedad, así como por reunir los requisitos legales establecidos en los propios Términos de Referencia, estaban en posibilidad de interesarse en la realización de la auditoría, varias de ellas manifestaron que ante los plazos fijados para realización de los trabajos, resultaba imposible cumplir con ellos. 
En virtud de que por acuerdo de los partidos se había propuesto al Consejo General del IFE la creación de un Consejo Técnico del Padrón Federal Electoral, responsable de la supervisión y vigilancia de todos los trabajos relativos a la auditoría externa, punto sobre el que volveré más adelante, los partidos convinieron en solicitar a dicho Consejo la revisión y modificación de las bases de la auditoría externa.

Finalmente, por recomendación del Consejo Técnico, el contrato fue adjudicado a la empresa Mckinsey de México, S.A. de C.V. como integradora del Proyecto, la que junto con otras siete empresas de reconocido prestigio en el mercado se responsabilizaron de las tareas de la auditoría.

La auditoría externa al Padrón Federal Electoral fue aprobada por el Consejo General el 28 de febrero de 1994, misma fecha en que fue aprobada la creación del Consejo Técnico del Padrón Electoral, como instancia de colaboración y coadyuvancia ciudadanas en los programas y actividades institucionales relacionadas con la integración del Padrón Electoral. A propuesta de los partidos el Consejo General aprobó el nombramiento de 11 distinguidos científicos y profesionistas mexicanos para integrar ese Consejo.

La auditoría externa fue llevada a cabo sin demérito de la verificación muestral nacional que los partidos políticos habían aprobado realizar a través de la Comisión Nacional de Vigilancia del Registro Federal de Electores con fecha 25 de noviembre de 1993.

Adicionalmente, como producto de las conversaciones entre los partidos políticos, y en los marcos del Acuerdo del 27 de enero de 1994, se tomaron diversas medidas prácticas para asegurar a los partidos la mayor transparencia en la integración del Padrón Electoral:

- Se aprobó modificar la fecha límite para la obtención de la Credencial para votar con fotografía, señalándose como nueva fecha el 12 de junio de 1994.

- En consecuencia, se aprobó que las listas nominales de electores fueran entregadas a los partidos para su revisión, impresas en medios magnéticos, el 30 de junio de 1994, e impresas en papel el 21 de julio de 1994.

- Se realizó la exhibición de las listas nominales de electores en todos los módulos para entrega de credenciales para votar con fotografía instalados en todo el país del 1 al 20 de abril de 1994. Dicho plazo fue ampliado a solicitud de los partidos políticos por 10 días naturales. 
- El Consejo General aprobó el 20 de julio de 1994 una segunda exhibición de las listas nominales de electores en los inmuebles que ocupan las oficinas sede de los ayuntamientos en todo el país, misma que se llevó a efecto del 10 al 20 de agosto de 1994.

- En la misma sesión el Consejo General aprobó los lineamientos para el cotejo de las listas nominales entregadas a los partidos políticos con las recibidas por los presidentes de las mesas directivas de casilla.

Todos esos acuerdos fueron propuestos por los partidos políticos, singularmente de los tres de mayor peso electoral, o en su oportunidad por los Consejeros Ciudadanos. En todos los casos requirieron para su instrumentación de recursos financieros, materiales y humanos extraordinarios, y en no pocos casos hubo que exigir a los ciudadanos que integrarían las mesas directivas de casilla tareas adicionales a las contempladas por la ley.

La declaratoria de validez del Padrón Federal Electoral fue realizada por el Consejo General del IFE en su sesión del 20 de julio de 1994 siendo aprobada, a propuesta de los seis Consejeros Ciudadanos, por 10 votos a favor y uno en contra, (el del Consejero representante de la primera minoría en la Cámara de Senadores).

He dicho, con fundamento en los estudios y pruebas de consistencia practicados al Padrón Electoral, que México cuenta, gracias al esfuerzo de los ciudadanos, los partidos y las autoridades electorales, con uno de los mejores padrones de inscripción voluntaria del mundo. Así lo acreditaron los propios ciudadanos que acudieron a las urnas el 21 de agosto, y lo certifica la opinión de la misión técnica de la Organización de las Naciones Unidas.

\section{Prerrogativas en materia de radio y televisión}

Uno de los puntos que mayor controversia despierta, en relación a los procesos electorales federales, es el acceso de los partidos a los medios masivos de comunicación electrónica. El debate ha discurrido en México por dos frentes principales: el de los tiempos gratuitos otorgados por el Estado a los partidos, y el de la equidad, imparcialidad y objetividad de los noticieros de Radio y Televisión. 
En el primer aspecto, en la mesa de Barcelona se analizaron las distintas opciones al alcance, conforme a la legislación y prácticas vigentes en materia de tiempos de que el Estado dispone, con el fin de otorgar un incremento sustancial en beneficio de los partidos políticos. Por consenso se aceptó la propuesta de incrementar los tiempos gratuitos en radio y televisión en $180 \%$ respecto de lo otorgado a los partidos en el proceso federal electoral inmediato anterior, distribuyéndose los tiempos adicionales en una proporción atemperada equivalente a los resultados electorales de cada partido en esa misma elección.

Con cargo al presupuesto del IFE, se otorgaron espacios en radio para la emisión de mensajes publicitarios a cada partido, que fueron distribuidos también en relación a sus resultados electorales anteriores, y se obtuvo de parte de la Cámara del ramo un trato similar al que se otorga a sus grandes anunciantes, con lo que por cada mensaje pagado el partido beneficiado recibió, sin costo, uno adicional.

Por lo que hace a la equidad, imparcialidad y objetividad de los espacios noticiosos en radio y televisión, y después de intercambios de opiniones entre los partidos y sus asesores en esta materia, la Comisión de Radiodifusión del IFE, integrada por representantes de los nueve partidos políticos nacionales, aprobó por unanimidad, el 15 de febrero de 1994, los lineamientos generales aplicables en los noticieros de radio y televisión, respecto de la información o difusión de las actividades de campaña de los partidos políticos.

Sin embargo, pese a esas medidas, las propuestas de varios partidos respecto de lo que consideraban inequidad y parcialidad en el tratamiento de sus campañas en dichos medios, obligaron a adoptar nuevas medidas. De esa forma, el 18 de junio de 1994, a propuesta de los Consejeros Ciudadanos, el Consejo General aprobó un acuerdo por el cual se exhortó a los medios de comunicación a proporcionar información veraz, objetiva, equilibrada, plural y equitativa respecto de las campañas electorales y los candidatos; recomendándose en particular a los medios de comunicación electrónica para que, además de cumplir con los principios antes señalados, respetaran los lineamientos generales aprobados por la Comisión de Radiodifusión del IFE.

A unos cuantos días de la elección, y a nueva propuesta de los Consejeros Ciudadanos, el Consejo General aprobó una última recomendación dirigida tanto a los medios electrónicos como a los impresos. 
Como parte de las discusiones interpartidistas sobre este tema, y también en relación al punto 4 del Acuerdo del 27 de enero - que a la letra decía:

"4. Impedir el uso de los recursos y programas públicos a favor de cualquier partido político o campaña electoral”.

Los partidos llegaron al acuerdo de solicitar al presidente de la República la suspensión de la propaganda en radio y televisión de los programas Procampo y Pronasol durante el mes de agosto, solicitud que fue aceptada por el Titular del Poder Ejecutivo.

En ese mismo tenor, los partidos acordaron suspender su propaganda pagada en radio y televisión durante los diez días previos a la jornada electoral, con excepción de la referida a los actos de cierre de campaña de sus candidatos presidenciales.

A las medidas anteriores deben sumarse las facilidades otorgadas por el Gobierno de la República que en forma gratuita puso a disposición de las estaciones de radio y televisión interesadas la señal de transmisión de los debates públicos realizados entre los candidatos del PAN, PRI y PRD. De igual forma, a solicitud de los partidos políticos, se procedió de manera similar con los cierres de campaña de sus candidatos a la presidencia de la República. Por vez primera en la historia de México, los actos de cierre de campaña de los tres partidos mayoritarios fueron transmitidos en vivo y en directo a toda la República, tanto por canales de señal libre como por el sistema de televisión por cable.

Coincido con muchos sectores y personalidades de la sociedad mexicana al opinar que en materia electoral, y en particular en este asunto de los medios de comunicación, aún nos falta por avanzar. Que será necesario arribar a nuevos acuerdos entre los partidos, pero sobre todo a nuevas prácticas y nuevas relaciones entre el Estado, los partidos y los medios de comunicación, con el fin de arribar al cumplimiento cabal de los principios de equidad, imparcialidad y objetividad en materia de información.

Ello deberá lograrse sin menoscabo de los derechos y libertades de expresión e información que nuestra Constitución consagra. Así lo he manifestado en distintos foros, e incluso en mi intervención del 12 de septiembre de 1994 señalé como uno de los cuatro puntos de una nueva agenda de reformas por realizarse la definición más precisa sobre el papel que juegan los medios de comunicación en la contienda electoral. Sin embargo, dejo constancia de la voluntad y decisión de la Cámara Nacional de la Industria de Radio y la Televisión, la cual 
siempre apoyó las nuevas modalidades que el IFE y un servidor le solicitamos.

Con objetividad y buena fe, nadie puede negar los avances registrados durante 1994; en muchos países se ha enfrentado esta problemática por la vía simple de negar a los partidos acceso a tiempo gratuito en los medios de comunicación, privilegiando los derechos de los propietarios de los medios. En México lo hemos empezado a resolver privilegiando los derechos de la sociedad y protegiendo el interés de las organizaciones políticas, sin poner en entredicho las garantías legales que protegen a los propietarios o concesionarios de los medios. En esta, como en otras materias, la experiencia electoral mexicana es hoy punto de referencia para otras naciones y para organismos internacionales.

\section{Delitos electorales y fiscal especial}

El tema de la penalización de conductas delictivas en materia electoral es de reciente discusión en México. No fue sino hasta 1990 cuando se introdujo en el Código Penal la primera sistematización de los delitos electorales creándose un capítulo particular en esta materia.

Los partidos participantes en las conversaciones de Barcelona, en particular el Partido Acción Nacional, consideraron que era necesario avanzar de manera sustantiva en materia de la penalización de los delitos electorales, de forma tal que la severidad de las penas operara de entrada como un factor de desaliento a la comisión de los ilícitos.

Tanto partidos como candidatos habían manifestado su interés en avanzar por ese camino, de forma tal que ya desde el Acuerdo del 27 de enero de 1994 se estableció lo siguiente:

“7. Para dar mayor garantía de legalidad al proceso electoral, se explorará ante la Procuraduría General de la República la posibilidad de nombrar un fiscal especial para perseguir delitos electorales".

Desde las primeras reuniones los partidos acordaron que el PAN fuese el ponente de un anteproyecto de reformas al Código Penal en materia de delitos electorales. Fueron analizados y corregidos varios anteproyectos, hasta llegar a uno de consenso que se presentó a la consideración de los legisladores de los tres partidos mayoritarios de la Cámara de Diputados, habiendo merecido la aprobación del H. Congreso de la Unión. 
En forma simultánea, los partidos iniciaron intercambios de propuestas para Fiscal Especial, en los términos del punto relativo antes citado y después de haber recibido la opinión positiva del C. Procurador General de la República.

Múltiples personas fueron propuestas para este cargo, llegar a consenso sobre una fue extremadamente difícil; sin embargo en seis casos se logró y la persona en cuestión no pudo aceptar, lo cual retrasó llegar a la designación de ese fiscal.

Como es del dominio público, las conversaciones de Barcelona concluyeron sin que los partidos hubiesen llegado a un acuerdo por consenso para el nombramiento del Fiscal Especial, fundamentalmente por los reiterados vetos del PRD a las propuestas presentadas. Ante tal situación, y visto el riesgo de que el poco tiempo disponible hiciera imposible el cumplimiento de uno de los puntos pactados el 27 de enero, después de consultar a los dirigentes de todos los partidos políticos, y con reserva de sólo uno de ellos, procedí a proponer al C. Procurador General de la República el nombramiento del Lic. Ricardo Franco Guzmán como Fiscal Especial para delitos electorales.

Estoy convencido de que las reformas al Código Penal fueron necesarias, que coadyuvaron a desalentar la comisión de ilícitos electorales para la mejor vía que es la de la prevención y la disuasión, pero no puedo dejar de reconocer que existen problemas en los textos aprobados que dejan lugar a dudas o lagunas para su aplicación. Si en alguna materia del derecho el juez debe apegarse estrictamente a lo establecido por el legislador, esa es la materia penal, cualquiera que sea su género específico. Creo que a la luz de la experiencia, y con mayor tiempo de por medio, el Poder Legislativo podría entrar a una revisión detallada del capítulo de delitos electorales en el Código Penal para perfeccionar las normas ahí contenidas.

De igual manera, creo que la constitución de una Fiscalía Especial para delitos electorales dentro de la PGR tuvo su razón de ser en las condiciones particulares del proceso federal electoral de 1994. Pero la experiencia nos indica los riesgos que se corren al someter al ámbito de la negociación política la designación de los servidores públicos responsables de perseguir los delitos, así como de los de la aplicación de la justicia. 


\section{Observadores electorales y visitantes extranjeros}

La reforma electoral de 1993 introdujo por primera vez en la legislación de la materia la figura de los observadores electorales nacionales, figura y práctica que se venían desarrollando en México desde 1989. $\mathrm{Al}$ inicio de las conversaciones de Barcelona, los partidos convinieron en la pertinencia de someter a revisión las normas que habían sido aprobadas apenas unos meses antes, debido a las múltiples solicitudes recibidas de diversos organismos de observación electoral que se quejaban de una excesiva reglamentación, e incluso de privación de derechos fundamentales. En mi carácter de presidente del Consejo General del IFE me reuní en varias oportunidades con los dirigentes principales de esos grupos a fin de recibir sus opiniones, comentarios y propuestas, mismas que trasladé a los partidos para su debida consideración.

Desde distintos ángulos de enfoque, los tres mayores partidos coincidieron en la pertinencia de simplificar los requisitos que la ley establecía para los observadores nacionales con la convicción de que toda forma de aliento a la participación ciudadana en nuestros comicios debía ser impulsada, de esa forma se propuso la reforma del párrafo 3 del artículo 5 del COFIPE, misma que fue aprobada por el H. Congreso de la Unión.

Después de haber consultado con los partidos políticos, y por instrucciones del Presidente de la República, giré invitación al Secretario General de la Organización de las Naciones Unidas para enviar a México dos misiones técnicas en materia electoral: la primera con el objetivo de realizar un informe sobre el sistema electoral federal mexicano; la segunda como misión de asistencia para los grupos de observadores electorales nacionales, dado el merecido y reconocido prestigio que la Unidad de Asistencia Electoral de la ONU tiene en amplios sectores de la comunidad internacional. La invitación fue aceptada y las dos misiones desarrollaron sus tareas con pleno respeto a nuestra soberanía, a las leyes electorales y a las autoridades y partidos.

Su contribución fue de singular importancia para el desarrollo del proceso electoral federal de 1994. La misión de estudio elaboró un detallado reporte que ha sido presentado a todos los interesados en México y al Secretario General de la ONU (Ver, ONU, Informe el Grupo de Expertos sobre el Sistema Electoral Mexicano). 
Por su parte, los asesores de la Unidad de Asistencia Electoral de la ONU dieron su apoyo a grupos de observadores nacionales, a los que asesoraron en técnicas y normas para una observación profesional e imparcial, así como en el levantamiento de encuestas para conteo rápido de resultados al día de la jornada electoral. Cabe destacar que en todo momento los expertos de la ONU se abstuvieron de validar o descalificar el trabajo de los Grupos de Observadores, limitándose a señalar el cumplimiento o incumplimiento de las reglas generales aplicadas por Naciones Unidas en esta materia.

Como complemento a este esfuerzo y a iniciativa de un servidor, misma que hicieron suya los Consejeros Ciudadanos del Consejo General del IFE, se constituyó un fideicomiso, con fondos de origen tanto público como privado, para el apoyo de la cobertura de casillas en zonas rurales alejadas, por representantes de partido $\mathrm{u}$ observadores electorales nacionales.

Según los datos del Instituto Federal Electoral, un total de 81,620 ciudadanos mexicanos fueron acreditados como observadores electorales para la jornada del 21 de agosto de 1994, cifra que por sí misma da cuenta de la magnitud del esfuerzo realizado. La sociedad ha conocido los informes presentados por los grupos de observadores, toca a ella, y a los partidos políticos, evaluar cuál es el compromiso de imparcialidad y objetividad, cuáles cumplieron ese compromiso y estuvieron a la altura de la responsabilidad que contrajeron.

Respecto de los visitantes extranjeros, esta figura, llevada a nuestra legislación electoral, fue la forma que los partidos políticos encontraron para abrir cauce a la presencia de grupos y personalidades interesadas en nuestros procesos electorales. Desde finales de 1993 diversos grupos y personalidades del extranjero habían manifestado, por diversos medios, su interés en presenciar los comicios mexicanos; de igual forma, varias organizaciones mexicanas habían expresado interés en invitar a grupos extranjeros, principalmente de promoción y defensa de los derechos humanos, a ver a México con motivo de las elecciones federales de 1994.

Los representantes de los tres mayores partidos políticos ante la mesa de conversaciones de Barcelona, después de analizar con detenimiento las distintas facetas que están involucradas en el asunto, llegaron a la conclusión de que la norma constitucional que reserva en exclusiva a los ciudadanos mexicanos el derecho a participar en la política interna debía permanecer sin modificación. Sin embargo, 
considerando la voluntad de apertura que caracterizó a todo el proceso electoral, convinieron en la necesidad de introducir en el COFIPE una disposición que permitiese atender el interés de personas y grupos de extranjeros que de manera legítima habían manifestado interés por venir al país a presenciar los comicios.

La fórmula adoptada consistió en facultar al Consejo General del IFE para que, con motivo de los procesos electorales, expida convocatoria pública invitando a personas y organismos del extranjero a presenciar los comicios mexicanos bajo la calidad de "visitantes extranjeros" (artículo 82, párrafo 2, COFIPE).

Aprobada la reforma por el H. Congreso de la Unión, el Consejo General del IFE resolvió encomendar a los Consejeros Ciudadanos la presentación de un proyecto de convocatoria, en el cual se otorgó a los partidos políticos la iniciativa para proponer a los grupos y personas que serían invitadas. Para el proceso electoral federal de 1994 se acreditaron ante las autoridades mexicanas un total de 934 personas bajo la calidad de "visitantes extranjeros" interesados en conocer el desarrollo de los comicios.

\section{Otros puntos de acuerdo}

Las conversaciones derivadas del Acuerdo Nacional del 27 de enero de 1994 abordaron múltiples aspectos del proceso electoral, en muchos casos las soluciones se tomaron aun antes de concluir la mesa de Barcelona, en otros, dejaron el terreno abonado para que el nuevo Consejo General que inició sus trabajos el 3 de junio de 1994 pudiese avanzar y tener rápidamente resultados.

Me limitaré a enunciar los acuerdos y procedimientos más significativos, la mayoría de los cuales no requirieron reforma legal, aprobados por el Consejo General entre febrero y agosto de 1994.

- Boletas adheridas a un talón con folio para facilitar su control y distribución.

- Líquido indeleble patentado por un científico mexicano, validado por la Escuela Nacional de Ciencias Biológicas del IPN, cuya efectividad ha sido acreditada por todas las pruebas efectuadas, 
pero sobre todo por los propios ciudadanos el día de la jornada electoral.

- Mamparas y elementos modulares en cada casilla electoral para garantizar el secreto del voto.

- Designación de los ciudadanos que habrían de integrar las mesas directivas de casilla mediante un procedimiento de doble insaculación, primero por el mes de nacimiento y luego por la primera letra del apellido paterno, método propuesto por el PRD.

- Capacitación de los ciudadanos que resultaron sorteados conforme al método anterior con supervisión de los partidos políticos en todas las fases del proceso.

- Acuerdo del Consejo General del IFE por el que se prorrogó el plazo y se simplificó el registro de representantes de partidos ante las mesas directivas de casilla.

- Acuerdo del Consejo General que reguló la contratación y desempeño de los asistentes electorales, reduciendo su número y sujetando su actuación al mandato expreso de los Consejos Distritales.

- Acuerdo del Consejo General del IFE para que los paquetes electorales no puedan ser destruidos antes de seis meses después de la conclusión del proceso electoral.

\section{Sistema de resultados oportunos y conteos rápidos}

Los acuerdos de Barcelona, las reformas legales que de ellos se derivaron y el conjunto de medidas adoptadas de común acuerdo entre partidos y autoridades electorales constituyeron una sólida base para la preparación de la jornada electoral, etapa en que se resumen los actos previos de todo el proceso. Garantizada la intervención y vigilancia de los partidos en todos los actos de la autoridad electoral, asegurada la imparcialidad de los funcionarios de casilla mediante el sistema de doble insaculación, confirmada la confiabilidad del padrón electoral y las listas nominales de electores y abastecidas todas las casillas del material electoral y los elementos modulares para garantizar el secreto del voto, quedaba por resolver la implantación de un sistema de resultados oportuno que permitiera al Consejo General del IFE informar a la sociedad, con oportunidad y veracidad, de los resultados de la elección. 
El Programa de Resultados Electorales Preliminares es una atribución y un mandato que el COFIPE confiere al Director General del Instituto Federal Electoral, mientras que por norma expresa del mismo ordenamiento jurídico, el propio Director General tiene la facultad discrecional de ordenar la realización de estudios que permitan conocer las tendencias electorales el día de la elección, pero los resultados de esos estudios sólo pueden ser dados a conocer al público previo acuerdo del Consejo General. (Artículo 89.1.incisos I y II)

Después de varias conversaciones entre los representantes de los partidos políticos y con los Consejeros Ciudadanos y del Poder Legislativo, solicité del Director General del IFE la mayor apertura y transparencia en el diseño y operación del Sistema de Resultados Preliminares (PREP). Todos los miembros del Consejo General fueron informados a detalle de las características técnicas del Sistema y el propio Consejo acordó las normas a que estaría sujeta su operación.

El sistema fue sometido a una auditoría previa a su entrada en funcionamiento, certificó que las memorias de la base de datos se encontraban en ceros y que no existía posibilidad alguna de interferencia o irrupción de agentes extraños al Sistema. La auditoría fue realizada por una empresa independiente en presencia de asesores técnicos representantes de los miembros del Consejo General.

Para evitar manipulación o distorsión de la información acumulada por el sistema durante las primeras horas posteriores al cierre de las casillas y la llegada de resultados, los partidos convinieron por consenso en que el PREP estaría cerrado hasta en tanto no se acumularan los resultados del 15\% de las casillas instaladas en el país. Durante el lapso que mediara entre el inicio de la operación del sistema y el cumplimiento de ese requisito, al sistema sólo tuvieron acceso los asesores técnicos representantes de los miembros del Consejo General del IFE.

Por razones de seguridad el PREP contó con un sistema de réplica instalado fuera de las instalaciones centrales del IFE. A ese sistema también tuvieron acceso los asesores técnicos de los miembros del Consejo General, sólo que por la misma razón esos asesores estuvieron aislados hasta que habiéndose cumplido el requisito de acumulación del $80 \%$ de las casillas culminaron su trabajo.

El PREP funcionó adecuadamente y una vez cumplido el requisito para el módulo central - $15 \%$ de las casillas - quedó abierto a la consulta de todos los interesados hasta el término de su función. Debe asentarse que el PREP no capturó el $4 \%$ de todas las actas porque las 
actas que debían servir para la transmisión de los datos fueron introducidas en los paquetes electorales. La información se proporcionó a los partidos y a todos los miembros del Consejo General conforme fue recibida y procesada. Actualmente se le está realizando una auditoría al PREP y terminada ésta, su resultado se hará público.

Por lo que hace al Conteo Rápido de resultados electorales, en múltiples ocasiones expliqué mi posición en el sentido de impulsar la realización de ese tipo de estudios por parte de organizaciones de la sociedad, de forma tal que hubiese múltiples testimonios de la firmeza de las tendencias reportadas y que esa condición se convirtiese en lo que llamé un "colchón de confiabilidad". Para apoyar la realización de estudios serios, basados en metodologías de validez científica, el Consejo Técnico del Padrón Electoral elaboró y publicó los mínimos metodológicos a que debían sujetarse los estudios de Conteo Rápido.

Se realizaron, además del ordenado por el Directorio General del IFE, un total de 12 conteos rápidos por otras tantas organizaciones de la sociedad y partidos políticos. Todos coincidieron en las tendencias registradas para los tres mayores partidos, y el del IFE, que fue uno de los últimos en ser dados a conocer la noche de la elección, se ubicó en los mismos rangos de resultados que los realizados por las organizaciones distintas a la autoridad electoral.

La experiencia vivida en esta materia el 21 y 22 de agosto de 1994 deja lecciones muy valiosas para el futuro, demuestra las virtudes de un trabajo conjunto, orientado por los mismos intereses de servicio a la sociedad, entre las organizaciones no gubernamentales, los partidos políticos y la autoridad electoral, la ciudadanía y los partidos conocieron tendencias firmes de resultados a las pocas horas del cierre de las casillas.

\section{La jornada electoral}

Una característica que parecía consubstancial a los procesos electorales federales era la generación de conflictos el día de la elección. Quien lea las actas de las sesiones del máximo órgano de dirección electoral federal entre 1979 y 1991 podrá constatar que los acuerdos construidos a lo largo de meses quedaban olvidados en el curso de la jornada electoral. Las sesiones permanentes de los órganos de direc- 
ción electoral quedaban marcadas por la multiplicidad de denuncias de irregularidades. Así ocurrió en diversas jornadas electorales. La historia cambió en 1994.

La sesión permanente del Consejo General dio inicio a las 8 horas del 21 de agosto de 1994, misma hora en que por ley deben abrir las casillas electorales. Después de escuchar los mensajes de los representantes de los partidos políticos y consejeros del máximo órgano de dirección electoral del país, y atendidas las diversas propuestas de procedimiento de los propios miembros del Consejo, la Presidencia decretó un receso para permitir a los asistentes a la sesión acudir a votar. Al reanudarse la sesión, el problema que se presentó, y que después se confirmaría como el de mayor importancia en toda la jornada electoral, fue el relativo a las casillas especiales.

No abundaré en el tema. Sus motivos han sido ampliamente explicados por los Consejeros Ciudadanos en el informe que con ese motivo presentaron al Consejo General. La única explicación al conflicto que se suscitó es la que corresponde a los hechos: los partidos políticos, en la "feria de las desconfianzas" que caracterizó todo el proceso electoral, prefirieron reducir el número de casillas y la dotación de boletas electorales en las llamadas casillas especiales. La extraordinaria afluencia de votantes y los movimientos de migración interna de la población se toparon con una norma que no los había tomado en cuenta.

Lamentablemente esa circunstancia, que nada tiene que ver con el dolo o la mala fe, hizo que un número reducido, pero en cualquier forma digno de tomarse en cuenta, de ciudadanos que se encontraban por circunstancias diversas fuera del ámbito territorial de su sección electoral, no pudiesen ejercer su derecho al sufragio.

Más allá de esa circunstancia prevista, la jornada electoral transcurrió en orden, así lo reflejan las actas de los órganos de dirección central y desconcentrados del IFE. Su característica principal fue la extraordinaria respuesta de los ciudadanos, que en número de 35545831 acudieron a ejercer su derecho al sufragio.

Esa extraordinaria respuesta ciudadana es el mejor balance que puede hacerse de los meses previos, del esfuerzo conjunto de sociedad, partidos y gobierno por avanzar en el perfeccionamiento de nuestra democracia. Esos millones de votos fueron el mejor testimonio de la voluntad de un pueblo que quiere seguir avanzando en la democracia y en la justicia. 


\section{Ejercicio de facultades del presidente del Consejo General del IFE}

Hay diversas formas de asumir las funciones que a uno le corresponden en virtud del cargo que se ostenta. Al llegar a la Presidencia del Consejo General del Instituto Federal Electoral me propuse actuar, como siempre lo he realizado en las diversas responsabilidades que he desempeñado, con verdadero compromiso y responsabilidad; viendo únicamente por el bien de México.

Nunca traté de cuidarme personalmente, sino de cuidar a México. Fui imparcial y tolerante pero cuando fue necesario puntualizar y polemizar, lo hice con convicción. Siempre actué de acuerdo con el principio de legalidad. La Constitución y la Ley fueron mi guía. Por ello considero pertinente manifestar cómo cumplí con las atribuciones expresas que el Código Federal de Instituciones y Procedimientos Electorales atribuye al Presidente del Consejo General del IFE.

Se puede incluso pensar que, en algunos casos, actué con pasión. Sí, con la pasión que deriva de la razón y de quien dice su verdad, en la que cree profundamente porque está basada en hechos, y pruebas y más pruebas.

Por razones de tiempo, este es un informe breve al cual le faltan matices y muchas explicaciones, las cuales se las debo a la sociedad y es por ello, como ya he dicho en diversas ocasiones, que me propongo profundizar sobre la verdad de este proceso electoral federal de 1994.

En mis atribuciones de presidente del IFE, como ya señalé en párrafos anteriores, me propuse:

1) Velar por la unidad y cohesión de las actividades de los órganos del IFE.

Desde la primera sesión en que tomé posesión como Presidente del Consejo General del IFE, que fue en la sesión extraordinaria del 27 de enero de 1994, afirmé en ese entonces, como lo sigo creyendo ahora y siempre, mi firme convicción de que la legalidad es el marco de referencia para todas y cada una de las actividades de todos y cada uno de los órganos desconcentrados de este Instituto, por eso, en aquella ocasión, que fue la primera en la que tuve el honor de presidir ese organismo, expresé que: "La sociedad tiene muchas expectativas en este Instituto y en todos 
nosotros. No la defraudemos. Hagamos que nuestros actos estén regidos por la ley, la responsabilidad, la concordia y los intereses del país. (Por tanto) Declaro que mi actuación estará regida exclusivamente por nuestra Constitución, la ley y las disposiciones de este Instituto"... "Si alguien me pidiera que me aparte de las normas, no lo haría. La imparcialidad será mi regla y mi guía”.

Este principio de Legalidad, como principio básico y rector de los actos tanto del Consejo como de esta Presidencia, lo reiteré en la sesión ordinaria del día 21 de agosto de 1994, cuando en esa ocasión declaré: "Como Presidente del Consejo General del Instituto Federal Electoral, refrendo el compromiso de legalidad e imparcialidad de la autoridad electoral"... "Reafirmo mi compromiso personal con México y con el apego a la ley, no me separaré de la ley por ningún motivo. El pueblo de México merece una jornada electoral ejemplar. La voluntad del pueblo mexicano es sagrada”.

Sin embargo, estoy consciente de que no sólo el cumplimiento estricto y puntual de la legalidad es el único medio que debe concurrir en la conducción de los trabajos de los órganos desconcentrados del IFE, en lo general, así como del Consejo General, en lo particular. Adicionalmente, siempre he creído que para una convivencia civilizada y productiva, el principio de la legalidad debe ser acompañado de otros principios, como el respeto mutuo a las personas y sus ideas, así lo manifesté en la sesión ordinaria del día 21 de agosto de 1994: “... quiero expresar mi respeto a todos y los partidos políticos de México que representan la pluralidad que tiene nuestro país...”.

Por último, en lo concerniente al principio de Imparcialidad, en la sesión ordinaria del 18 de junio de 1994 expuse lo siguiente: "Ustedes habrán visto que generalmente no voto ni intervengo a menos de que lo considere esencial... Como se ha dicho, mi autoridad es moral; pero en el peor de los casos, o en el mejor de los casos, sería un voto. Voto que generalmente no ejercito para tratar de mostrar mi imparcialidad. Pero si les quiero decir que no tengo ninguna imparcialidad cuando se ataca a México. No tendré ninguna imparcialidad cuando sienta que se está lesionando a México".

Es preciso reiterar, una vez más, de que no me cabe duda de que con la práctica de estos principios, nuestras instituciones cí- 
vicas y electorales, los partidos políticos y demás organizaciones sociales, así como los ciudadanos en lo general, se podrán desenvolver plenamente en un régimen de transparencia y equidad, ya que sólo con ellos la democracia alcanza sus fines últimos y trascendentes.

La Presidencia nunca hizo limitación alguna de la libertad de expresión que todos y cada uno de los miembros del Consejo General gozaron de manera amplia y sin límite de tiempo alguno. Asimismo, durante este periodo puse un muy especial énfasis por transparentar todas y cada una de las etapas que conformaron este proceso electoral, considerando que la sociedad mexicana no sólo demandaba unas elecciones limpias sino también creíbles.

Con base en estos principios rectores, es que durante la sesión especial del día 3 de junio de 1994, hice un atento llamado "A todos los mexicanos, a sus organizaciones políticas y sociales (para que)... por el bien del país,... reforcemos nuestros principios de moralidad política, uno de los cuales es el postulado de que siempre hay que decir la verdad, cualquiera que esta sea, la verdad únicamente la verdad", el cual reafirmo plenamente en este Informe que anexo para su conocimiento, con el propósito de que se conozca y difunda el hecho de que la preservación de la unidad de las actividades de los diversos órganos desconcentrados del IFE, a cargo de esta Presidencia, no fue, ni es, una mera facultad de índole declarativa y formal dentro del Código, sino que por el contrario, implicó un conjunto de compromisos sustanciales, a veces difíciles de lograr y mantener, pero siempre apegados a la ley y a todos aquellos principio rectores que sustentan y dan cauce a nuestra democracia en el sistema federal electoral.

2) Establecer los vínculos entre el Instituto y las autoridades federales, estatales y municipales, para lograr su apoyo y colaboración, en sus respectivos ámbitos de competencia, cuando sea necesario para el cumplimiento de los fines del Instituto.

El día 23 de marzo del presente año, se llevó a cabo en la sede del Instituto la firma de los Convenios de Colaboración entre el representante del Instituto Federal Electoral y los Gobiernos de cada una de las Entidades Federativas, con la asistencia de los Gobernadores Constitucionales de cada una de las Entidades y el Jefe del Departamento del Distrito Federal, los Secretarios 
Generales de Gobierno y las autoridades electorales locales de cada estado, el Director General y el Secretario General del IFE, y como testigo de Honor el Presidente del Consejo General de dicho Instituto.

Es necesario mencionar que la suscripción de estos Convenios se realizó siempre con estricto respeto de las competencias y atribuciones de cada uno de los Gobiernos locales. De igual forma se respetaron los derechos y prerrogativas de las organizaciones políticas y ciudadanas, en el ámbito de las respectivas legislaciones locales y federales.

Con la firma de estos instrumentos jurídicos de cooperación, el Instituto Federal Electoral interactúa con las Entidades Federativas y el Departamento del Distrito Federal para proporcionar y recibir, dentro de sus respectivas esferas de competencia, apoyos en las diversas materias que especifican las leyes y los respectivos Convenios.

3) Convocar y conducir las sesiones del Consejo.

A partir de la sesión extraordinaria del día 27 de enero de 1994, que fue cuando protesté como Presidente del Consejo General del IFE, he convocado y presidido hasta el día de hoy un total de 22 sesiones de Consejo, entre ordinarias, extraordinarias y especiales, las que tuvieran verificativo en las siguientes fechas del presente año:

1. Extraordinaria. 27 de enero.

2. Ordinaria. 28 de febrero.

3. Ordinaria. 17 de marzo.

4. Extraordinaria. 17 de marzo.

5. Ordinaria. 13 de abril.

6. Extraordinaria. 15 de mayo.

7. Ordinaria. 18 de mayo.

8. Extraordinaria. 18 de mayo.

9. Especial. 3 de junio.

10. Extraordinaria. 3 de junio.

11. Especial. 18 de junio.

12. Ordinaria. 18 de junio.

13. Extraordinaria. 20 de julio.

14. Ordinaria. 20 de julio.

15. Extraordinaria. 29 de julio. 

16. Ordinaria. 6 de agosto.
17. Ordinaria. 21 de agosto.
18. Ordinaria. 24,25 y 28 de agosto.
19. Ordinaria. 28 de septiembre.
20. Extraordinaria. 22 de octubre.
21. Extraordinaria. 26 de octubre.
22. Ordinaria. 26 de octubre.

En cada una de esas sesiones, la Presidencia se limitó, en casi la totalidad de sus intervenciones, a conducir las sesiones, otorgando la palabra a los consejeros y representantes que así la solicitaban, en estricto orden y sin mengua de su derecho constitucional de libertad de expresión, por lo que antes de que se procediera a poner a votación algún proyecto de Acuerdo, esta Presidencia siempre procuró consultar a la Mesa si había sido discutido suficientemente o si se debía seguir discutiendo, y sólo una vez que en votación económica o por consenso el Consejo General se pronunciaba en este respecto, era que se procedía a la votación final.

Sin embargo, cuando consideré oportuno hacer algún comentario, sugerencia o precisión, procedí en consecuencia, teniendo en mente el respeto por las opiniones y personas de los miembros de este Consejo. Por lo mismo, he creído y creo que la tolerancia y la mesura constituyen las mejores vías de acuerdo y beneficio mutuo. Para corroborar este dicho, bastaría con leer las actas de las diversas sesiones, para que se ponga de manifiesto que en innumerables ocasiones, los proyectos de acuerdo agendados para cada una de ellas se vieron enriquecidos con observaciones o propuestas alternativas, y también como, en muchas ocasiones, éstas fueron incorporadas después de fructíferos e interesantes debates.

4) Vigilar el cumplimiento de los acuerdos adoptados por el propio Consejo General.

Con respecto a esta facultad, la Presidencia del Consejo General mantuvo una vigilancia inmediata sobre aquellos acuerdos de la competencia directa del mismo Consejo. Sin embargo, el cumplimiento de esta facultad no se restringió a lo anterior, sino que en todo momento procuré estar atento al seguimiento de los acuerdos cuya ejecución competía a las Direcciones Ejecutivas y 
demás órganos directivos o consultivos del IFE. Además, dichas acciones de vigilancia eran examinadas en acuerdos periódicos de la Presidencia con el Director General del Instituto, así como en el análisis cuidadoso de los informes trimestrales que la Junta General Ejecutiva presentó con oportunidad.

Además de los actos ya descritos, en aquellos casos en que el Consejo General decidió adoptar acuerdos de la competencia exclusiva de algún órgano de tipo consultivo (como el Consejo Técnico del Padrón) que no estuviera dentro de la línea jerárquica del Instituto, o tratándose de las muy importantes exhortaciones que el mismo Consejo realizó durante el desarrollo del proceso electoral, la Presidencia mantuvo un seguimiento cercano, pero atento y respetuoso de dichos acuerdos, en cumplimiento de la facultad concedida para estos fines por el Código de la materia, pero, consciente de que los destinatarios eran individuos y organizaciones ajenas a los órganos electorales federales invariablemente se respetó la independencia, derechos y garantías que la Constitución y las leyes les otorgan.

Para facilitar el seguimiento de los actos que la Presidencia del Consejo General desempeñó durante su encargo, al final de este Informe se presentan anexos, el IV describe de manera resumida y sistemática los acuerdos adoptados durante las sesiones de Consejo en este proceso electoral federal, las votaciones respectivas y las propuestas alternas que a los mismos se hicieron por parte de miembros del propio Consejo; el anexo $\mathrm{V}$ presenta de manera sintética los acuerdos de índole normativa publicados en el Diario Oficial, que no sólo representaron el cumplimiento de lo prescrito por el COFIPE, sino que muchas veces establecieron normas y lineamientos, los cuales significaron también un punto culminante en la búsqueda de consensos entre los miembros del Consejo General y cuyo propósito fue beneficiar a los ciudadanos electores y a los partidos políticos, ya que hicieron más equitativos y transparentes cada una de las etapas del proceso electoral de 1994, dando así mayor credibilidad a los resultados electorales.

5) Recibir de los partidos políticos las solicitudes de registro de candidatos a la Presidencia de la República y la de candidatos a diputados por el principio de representación proporcional y someterlas al Consejo General para su registro. 
Para el proceso federal electoral de 1994, el Instituto recibió de los partidos políticos, dentro de los primeros quince días del mes de marzo, las solicitudes de registro para cada una de las candidaturas a la Presidencia de la República, como lo señala el artículo 177 párrafo 1, inciso b) del Código de la materia, y el artículo octavo transitorio, fracción XV, inciso d) del Decreto por el que se reforman, adicionan y derogan diversas disposiciones del propio Código publicado en el Diario Oficial de la Federación el 24 de septiembre de 1993.

El presidente del Consejo General, conjuntamente con el Director General y el Secretario General del IFE, atendió personalmente la recepción de dichas solicitudes, las que fueron presentadas en el siguiente orden cronológico:

- Partido del Trabajo

Sra. Cecilia Soto

1 de marzo de 1994

- Partido del Frente Cardenista de Reconstrucción Nacional.

Lic. Rafael Aguilar Talamantes

3 de marzo de 1994

- Partido Revolucionario Institucional

Lic. Luis Donaldo Colosio Murrieta

4 de marzo de 1994

- Partido de la Revolución Democrática

Ing. Cuauhtémoc Cárdenas Solórzano

5 de marzo de 1994

- Partido Popular Socialista

Lic. Marcela Lombardo

8 de marzo de 1994

- Partido Auténtico de la Revolución Mexicana

Ing. Álvaro Pérez Treviño

11 de marzo de 1994 
- Partido Acción Nacional

Lic. Diego Fernández de Cevallos

12 de marzo de 1994

- Partido Verde Ecologista de México

Lic. Jorge González Torres

14 de marzo de 1994

El Consejo General registró, de manera oficial, las solicitudes de candidaturas a la Presidencia de la República durante la sesión extraordinaria celebrada el 17 de marzo del presente año.

Como consecuencia de los lamentables hechos acaecidos en la ciudad de Tijuana el 23 de marzo de 1994, en los que perdió la vida el candidato a la Presidencia del Partido Revolucionario Institucional, Lic. Luis Donaldo Colosio Murrieta, el Partido ya mencionado, hizo uso del derecho de sustitución de candidatos que regula el art. 181.1 b) del COFIPE. Por lo cual se inscribió el día 30 de marzo de 1994 la solicitud de candidatura a la Presidencia de la República del Dr. Ernesto Zedillo Ponce de León, la que fue registrada por el Consejo General en la sesión celebrada el día 13 de abril del presente.

Asimismo, y con respecto de las solicitudes correspondientes a las candidaturas de diputados por el principio de representación proporcional, las cuales fueron presentadas por los partidos políticos dentro del plazo que señala la ley (del 1 al 15 de junio inclusive), el Consejo General conoció y aprobó dichas solicitudes de registro de candidaturas en la sesión especial del 18 de junio, en la que se registraron 3540 fórmulas de candidaturas correspondientes a las listas regionales de las cinco circunscripciones plurinominales, las que en los meses posteriores sufrieron modificaciones, debido a que los partidos ejercieron sus derechos de sustitución de candidatos, en los términos de la ley.

\section{REFLEXIONES FINALES}

México llegó al 21 de agosto de 1994 a una cita histórica: realizar elecciones en las que el compromiso común era la legalidad y limpieza. 
El objetivo se cumplió. Ello lo consta principalmente el pueblo de México. Desde luego que no desconocemos las anomalías e irregularidades que se dieron, pero en términos generales se desarrolló razonablemente bien. La mayoría de esas irregularidades y anomalías, afortunadamente, han sido remediadas por el magnífico trabajo que ha desarrollado el Tribunal Federal Electoral.

A partir de ahora los avances de los que he dado cuenta constituyen parte integrante del patrimonio democrático de la sociedad. No son perfectos, son perfectibles. Sociedad, partidos y autoridades deberán continuar en el empeño por dar a México el sistema jurídico y procedimental que lejos de prejuicios y desconfianzas haga de las elecciones método regular y confiable para renovar los poderes públicos.

El mérito por lo avanzado es de todos, nuestro único límite fue el estricto cumplimiento del mandato constitucional y legal que ordena la realización periódica de elecciones. Si hubiese habido más tiempo, seguramente hubiésemos completado la tarea en algunos aspectos que a nadie escapa que deberán seguir siendo temas a debate y punto de encuentro para el diseño de soluciones que contribuyan a la democratización integral de México. Tocará a otros protagonistas dar respuesta a las tareas que quedaron pendientes.

Quiero terminar expresando a todos los integrantes del Colegio Electoral, miembros de la LVI Legislatura de la Cámara de Diputados del H. Congreso de la Unión, mis mejores deseos para que en su delicada tarea de calificar las elecciones presidenciales los ilumine la frase que corona el salón de sesiones del Palacio Legislativo. "La Patria es Primero".

En la madrugada del 22 de agosto de 1994, antes de levantar la sesión del Consejo General del Instituto Federal Electoral, iniciada a las 8 horas del día anterior, expresé una reflexión final, la cual ahora, en este Informe personal, deseo refrendar:

"Creo que todos juntos realizamos las reformas constitucionales, legales y administrativas que han sido el marco jurídico de esta elección. Creo que no nos toca a nosotros juzgar estos aspectos, pero estoy seguro de que se dieron muchos pasos hacia adelante que ya van a ser irreversibles. También tendrán que seguirse dando más pasos de aquí para adelante". 